\title{
Architecture and Biological Systems
}

\section{ABSTRACT}

"Luxury at present can only be enjoyed by the ignorant; the cruelest man living could not sit at his feast, unless he sat blindfolded" (John Ruskin, 1905)

The emphasis on 'perform ative' architecture and practice has seen an increase in recent years partly due to the current economic and environmental crises. Developments in parametric design, monitoring and analysis software are an obvious part of the technical equation, which are leading to the 'finding of form' rather than the 'making of form'. We need to make sure we are not just 'performing' in a superficial way, though; adding a few analysis diagrams to our presentation repertoire is not enough. Simply cladding buildings with morphogenetic skins will not get us to where we need to go.

In our Information Age it is ironic that one of the main information areas that certain architects are looking at now is of the natural world - Biology. Michael Weinstock has stated that Physics was the driving force of the $19^{\text {th }}$ and $20^{\text {th }}$ century; Biology will be important in the $21^{\text {st }}$ century. In the midst of this environmental crisis it is time we understood more about the planet we inhabit. Human 'progress' has led us to this crisis and detachment from 'nature'. However, technology can help us understand these natural systems at another level then we previously had known. The study of Biomimetics is increasing in architectural curricula across the country. Is it superficial image making or an understanding of the systems and their performative aspects?

So far these examples are infinitely less complex than the natural world; they tend to be simplified algorithms at this point. Alfred Caldwell has stated that nature seems so complex and alive, but "nothing in nature is arbitrary". Have we imported enough of the parameters of life into our design equation? Do we need to be that literal and complex? If nature is not arbitrary, than presumably it is a system that can be learnt and studied.

This paper seeks to analyze the basic principles of Biomimetics and to study examples of the more optimistic, ecological models for architectural practice and the academy that are developing today in this area; hypothesizing on 
possible, future directions for our profession in this time of rapid change.

\section{WHY IS THIS RELEVANT NOW?}

Environmentalism is not a new issue. Historically, whether in the guise of conservationism or the arts and crafts movement environmental issues gained momentum as the world became more developed and industrialized. Recently there has been more mainstream acceptance of environmental concerns in the wake of the current global economic crisis, population boom and global warming. The building industry is a major player in this environmental crisis because it uses approximately one third to one half of all available resources. For this reason alone it is apparent that building processes, resources and systems should be critically reviewed. The environmental concern is not just about the shortage of future natural resources, but about the effect the pollution and waste has on human health issues, human psychology and further environmental impacts.

Star-based, willful architecture projects are diminishing for most. Tighter budgets mean that architects need more concrete reasons for their design decisions: there is a need for a larger sense of responsibility than many architects have shown in the recent past, a broader sense of 'ethics'. Making sure buildings 'perform' responsibly is a key issue today. Innovation and technological advancement are not important for their own sakes; developments need to be balanced in consideration with available resources and human culture and psychology. One of the main shifts that need to be made is away from the pressure of short-term goals to longer term ones. Experimentation and research must be focused on what we know and need. Change is a process and takes time, but there should be some sense of urgency in our current situation.

Nature is the ultimate in performance-orientated design so it is no wonder that attention is finally being paid to its processes. This coupled with increasingly levels of knowledge and tech- nology set the stage for a new level of more ecologically-based design. Architecture is moving past the idea of single object buildings and monuments and gaining more focus on a more ecologically-based, systems approach, like nature, where organisms function in relationship to each other and their entire surroundings.

One dilemma is how such a holistic approach might be evaluated. The academy seems to be embracing the idea of Biomimetics ('the abstraction of good design from nature'); courses are appearing at multiple institutions. In 2008, ACADIA (the Association for Computer Aided Design in Architecture) had a conference dedicated to this issue, 'Silicon and Skin; Biological Processes and Computation'. Business as usual (form-making) should be no longer acceptable.

\section{PRINCIPLES OF BIOLOGY RELEVANT FOR ARCHITECTURE}

In 1956 Kenneth Boulding, a systems scientist and philosopher, created a 'Theory of Organization' which organized structures into a hierarchy of complexity:

1. Frameworks: static structures.

2. Clockwork: predetermined movement.

3. Thermostats: feedback loops, homeostasis; ability to control, cybernetic systems.

4. The cell: metabolism, self-maintaining, life.

5. The plant: specialization, society of cells, rudimentary sensing, tropism (these normally stay in one place like buildings)

6. Animals, society of organs, refined sensing, mobility, communication, learning, self-awareness, emotion.

7. The human being: reason, abstraction, language, self-consciousness or inner sensibility, aesthetics, free will, a more elaborate sense of time and relationships.

Buildings and architecture are generally at the lower end of the spectrum, historically in the 
very bottom category. As we try to analyze our built environment's performance it makes sense to study the systems of the higher levels and to evaluate which components should be potential goals for architecture. Realizing that complexity for complexity's sake is not the critical answer.

Nature, even at the level of geology is dynamic; it is constantly changing, adapting, modifying and evolving, whether we are able to perceive this with the human eye or not. "In the morphogenesis of biological organisms, it is the animation of geometry and material that produce form. Geometry and material hierarchies produce dynamics." ${ }^{\prime 1}$

Some of the main characteristics of natural systems are:

1. Good economics of energy and materials: optimization.

2. Rich, diverse systems from small, relatively simple components and materials.

3. Form, structure and material are generally all interconnected.

4. Survival techniques are maximized: e.g. carrying capacity, the relationship to surrounding environments (ecological), usually always process-driven systems.

5. Always dynamic systems: all nature is constantly changing and adapting.

6. Self-organization techniques are utilized; they produce emergent behavior, from sub-cells to ecosystems (systems within systems).

Items 1 through 4, one could argue, are the more straightforward examples that are well on the way to being achieved in architectural design at this point and 5 through 6 are potentially more extreme. All of these criteria need to be looked at in more detail to understand what works and why. With regards to optimization, for instance, this has historically been treated very differently in biology verses buildings. In biology to achieve efficiency and optimization there is a high amount of redundancy and complexity in the material hierarchies. This redundancy allows adaptation to changing environments, and is a much less linear approach to the way we usually engineer buildings. Biology's stochastic process, rather than a deterministic one, generally means that the standardization of components and members is precluded.

Regarding materials, "biology makes use of remarkably few materials, and nearly all loads are carried by fibrous composites; cellulose in plants, collagen in animals, chitin in insects and silk in spider webs." ${ }^{2}$ These materials have much lower densities than those normally used by the construction industry. They work not because of this fact alone, but because of the way they are put together. For example, the same material is used in blood vessels as in more rigid bone. Fiber composites are anisotropic (the property of the material depends on a direction, e.g. a grain in wood). These materials generally provide higher levels of optimization then ones which are more homogeneous. Generally, they are good in tension and bad in compression (tension based systems per weight are usually more efficient than compression systems). This lack of performance in compression is solved in various ways in nature; either by pre-stressing the fibers so they hardly ever experience compression, the creation of fibrous networks where changes in orientation avoid compressive loads acting along fibers and finally the addition of minerals which help to carry the compressive loads.

Geometry, pattern-making and folding strategies are other very apparent teachers in the natural world. In human bone, for instance the cellular solids are polyhedral versus the more regularly organized, minimal surfaces equated with beehives.

Ecology is one of the sub-disciplines of biology that is very relevant to architecture today and 
often used as an adjective to projects and disciplines. It is 'the branch of biology that deals with the relationships between living organisms and their environment', (Oxford English Dictionary). The main point is to see an object as a system that relates to its surrounding systems (context) as a process. The main biological processes are photosynthesis (carbon dioxide chemical transfer to organic compounds using solar energy), reproduction (information transfer), metabolism (process of taking in energy for living processes and expelling waste), homeostasis (self-regulation) and hydrogen technology, There are also biological phenomena that are often the result of environmental stimuli, for example tropisms; geotropism, phototropism, hydrotropism and thigmotropism to name a few.

There are many more lessons to be learnt from nature and our environment, including entropy, synergy and cybernetic theory. Cybernetics is the study of control and communication; in biology primarily focusing on how animals adapt to their environment, and how information is passed from generation to generation. Artificial intelligence, feedback systems, selforganization and emergent theories are all subsets of cybernetics. Self-organization is widespread in animal architecture and behavior creating decentralized, distributed, emergent, complex, non-linear systems from simple, local rules. Surely we should be teaching these principles in our environmental control classes, so we can understand systems theory in a broader context.

\section{APPLICATIONS: HOW DO WE TRANSLATE THESE PRINCIPLES?}

How much of this knowledge is important to use for architects in the quest for performative design? It should not just be about superficial skin making or adding a couple of analysis diagrams to our presentations. Surely we should not just be making skins or buildings dynamic or be interactive just for the sake of it: this, in a pragmatic sense, can just create maintenance issues and be an energy hog. Do buildings need to strive to be alive? How interactive do we want/ need them to be? If we look at 'architecture without architects', generally in pre-industrialized societies, the built environment seemed to be in a more harmonious relationship with its natural environment. Building traditions developed over usually hundreds of years and generally used local materials, maximizing as many passive systems as possible (more akin to nature). This architecture was not alive, but was generally more informal in the sense that there was a level of adaptability and connection to a larger whole that was apparent. For some cultures this was also a result of people adding on and subtracting to their dwellings over generations rather than just moving or building new houses as the western world tends to do today. Most people ultimately want some control over their environment so a total topdown approach to design and planning sometimes inhibits the sense of freedom and life. As humans have the ability to have choices, free will, self-interest and self-awareness this tends to prevent any strictly predictive models from applying to human problems as they do in natural sciences. Although there is no point being nostalgic about the past there are lessons to be learnt, which coupled with our increased technological knowledge will hopefully lead to more satisfactory results that 'perform' at higher levels. Technologically we have advanced tools for design, fabrication and construction which mean we should be able to design 'smarter' environments for ourselves: we are no longer constrained by the concept of standardization in a literal way as an economic model.

We do need to view buildings and all the related systems as a longer term concept: one which factors, or tries to factor in all potential life-cycle costs. This implies a cultural shift or legislative shift at a minimum. How can you expect people to just suddenly be not interested in making quick profits in our capitalist society? There is obviously the demand from consumers that is shifting slightly, but generally this is a very slow, uneducated, media-driven process. 
In his book, Architecture of the Well-Tempered Environment, Reyner Banham spoke of two traditions in architecture; one with substantial structures and one without. Superficially it makes sense, to think that lighter, more temporary dwellings are the more sustainable tradition, but each case is specific to its particular situation. Generally more solid or heavy buildings could last for centuries, as long as they are adaptable programmatically. With the advances in computer simulation and digital fabrication we should at a minimum be relating form to basic thermal issues.

Ecological, inter-connected systems in the natural world have no separation of form, structure and material: they all act on one another and cannot be predicted by the analysis of any one separately or in a different context. Isn't this how architecture should be; critically sensitive to its region and holistic? In academia it is generally in studio where all our support/core classes supposedly come together. Shouldn't this 'coming together' be more than the typical studio class which is usually only about a third of our semester or quarter's required credits? Most curricula's separation of materials, structure and systems are a potential interfering issue. With the increasing specialization of professions and the academy it is imperative to get input from other areas of knowledge and experience to develop a holistic design strategy. The development of Building Information Modeling and Integrated Project Delivery (BIM/IPD) is, in theory, pushing us to a more integrated, cohesive model of working. But we need to make sure we are not just using this methodology to do business as usual. Using a $3 d$ digital database model in itself does not imply an interconnection of systems with its environment. It merely implies more potential coordination of existing rules of design and construction. We need to see buildings as interconnected, dynamic networks.

Relation-based aspects of parametric computer modeling programs are closer to the information-based processing in nature. New ordering methods with computational means; self-organization bottom up verses top down are a useful design tool today. With anything, though, it is important to remember that it is not just valid because one is using some contemporary technology. We need to move beyond this to be critical of the inputs and how they relate to a knowledge-based design aesthetic that is appropriate on many levels. We also have a long way to go computationally. Live analytical feedback loops via parametric software are continuously developing, but are still relatively complex and clunky. This generally means that optimization and simulation tools are still used for analysis after an initial design is developed rather than as a live, design generator.

Much of the embodied energy in buildings comes from the production of building materials; thus improvements of energy use in production processes is a crucial part of any overall strategy for energy conservation in the built environment. Much of the energy takes place in the manufacture of a few extensively used materials which involve high temperature kiln processes, notably clay bricks, cement, tiles and glass.

In most contemporary buildings walls become barriers to isolate space and separate us from nature; resolving this paradox is what forces buildings to include many of the technologies and infrastructure we use today. Living systems resolve this paradox by creating adaptive interfaces rather than barriers. Some recent advances are building walls that can be porous and permeated. Rain screens and double skins are just the first step in this process, to make buildings more breathable. Ultimately we need to be resolving this in tandem with the materiality, structure and form.

"The spider conducts operations that resemble those of a weaver, and a bee puts to shame many an architect in the construction of her cells. But what distinguishes the worst architect from the best of bees is this, that the architect raises 
his structure in imagination before he erects it in reality" Karl Marx, Das Kapital, (1867).

There is no design in biological evolution; it's fluid process works as an open systems regulated by the laws of nature only and is in contrast to the more rigid, authoritarian and oppressive system we generally use to design our built environments. Some could see this selforganizing approach to design as the first step in making the role of the architect redundant. Every technology needs to be designed, but in the short term at least, the emphasis towards this strategy may make the role of the architect unfamiliar. Architects would only become redundant if they did not make the transition themselves from a Cartesian-based world to a systems-based one. This necessary adjustment would apply to other disciplines too. The new 'systems' architect (in the living technology sense of the word) will need to be an interdisciplinary practitioner as a matter of survival.

\section{EXAMPLES}

Human interest in technology and nature probably goes back to the beginning of time. More recently one of the main associations has been with Frei Otto and his development of the Institute for Lightweight Structures and Conceptual Design, in Stuttgart, Germany. Current academic programs that seem to be embracing this methodology are generally approaching this issue beyond the traditional scope of architecture, in many cases incorporating or collaborating with individuals or groups from other disciplines. The Architectural Association in London, particularly the Emerging Technologies and Design Graduate Program (EMTECH) that includes George Jeronimidis, a doctor of physical chemistry and director of the Centre for Biomimetics at the University of Reading, has been the primary leader in the current approach to biomimetic design. The publications of its architectural faculty, Michael Hensel, Achim Menges and Michael Weinstock and their protégées are having a large impact on the profession today. One of their ex-students, Neri Oxman at MIT, is working on the the synergy between geometry, physical matter and energy, with the implication that modeling, analysis and fabrication occur simultaneously. To do this, she states that one must first abandon the conceptual structure of a divided and hierarchical process separating the analytic and the synthetic, and arrive at their ultimate integration. "A new philosophy of design is slowly emerging which anticipates and supports the merging of matter and energy on the way to proto-design."

The Lab Studio at UPenn initiated in 2007, is a hybrid research and design unit between the architecture department and the medicine and engineering institute. Their research is applied to both professions. The Center for Architecture and Situated Technologies (CAST) at the University of Buffalo has an emphasis on 'soft materials and the capabilities of an elastic, responsive architecture' and the Center for Architectural Science and Ecology (CASE), collaboration between SOM and RPI has a research trajectory on 'next-generation building systems.'

The development of smart materials is continually advancing. Smart materials are those that are potentially changeable and thus responsive to transient needs. There are generally two types; those that absorb an input energy and undergo a change (e.g. shape memory materials) and those that transform energy from one form to another (e.g. photovoltaics). The implied trajectory is that concrete (this alone counts for $5 \%$ of all carbon emissions) and metal (a limited resource) will be things of the past leading to more use of synthetic ceramics, polymers and composites. It is also interesting to note that nearly every material can be turned into a foam structure, which can relate to the cellular solids in nature, like bone. Many of these smart materials seem very two dimensional still and will hopefully be developed with form and structure, concurrently in the future, relating possibly to the structural and organizational principles learned from nature. 
The relationship between material and construction approaches also need to be connected to have really sustainable buildings; they need to be 'native' and responsive to their particular environment. Advances in freeform construction and additive fabrication methods in layers verses mold-making and machining from large blocks (subtractive methods), seems to have potential for future techniques. Direct, additive fabrication methods are generally more sustainable than subtractive methods. There are three approaches today that can create full-scale structures; the first is at Loughborough University, England; with their 'Threshold Deposition Device', the second is Enrico Dini's 'Monolite' process in Italy and the UK and the third is Behrokh Khoshnevis's, 'Contour Crafting' at USC. These printers, beyond the fact that no form work is needed, are also capable of incorporating local materials and mineral systems specific to the locale in their construction process. There is also the whole realm of research in robotics; whether as a tool for digital fabrication and/or construction.

Protocell technology builds on the belief that conventional materials will only take us so far on the road to sustainability. What these researchers suggest is that we need to parallel biology rather than trying to abstract some of the principles; making synthetic life, with the help of research in the field of biochemistry. This is perhaps the most extreme research philosophy related to nature. Although potentially alien to the natural world, it would speak the same language in terms of chemistry and physics. For many 'nature' is still an image relating to an Arcadian wilderness, that in reality no longer exists. Nature and humanity become more linked every day and with the development of protocells it becomes apparent that the relationship between the natural and manufactured is blurring too. Humans are in fact part of nature, so are not all our manufactured products natural too? Maybe this could be a positive; generally dualisms have tended to categorize and polarize issues and people rather than providing balance. This protocell technology is being re- searched at various institutions and universities around the world. Most of this research is making cells which are fairly simple chemically and so would be potentially totally economically viable. One research center is at Los Alamos, New Mexico where their protocells have just three components: 'a metabolism (the chemical processes used to obtain energy and create the protocell's building blocks), an information system (which instructs the metabolism) and a container (which keeps everything together).' Philip Beesley, an architect and Professor at the University of Waterloo, Canada recently incorporated this technology with his team in an installation representing Canada for the Venice Biennale, 2010; The Hylozoic Ground Project.

\section{CONCLUSION}

There are numerous examples of architects and academics incorporating biomimetic principles into their work. This happens at various scales, from installations to urban plans. Many of the examples mentioned incorporate a few of the issues apparent in biological systems. It is the holistic aspect that seems generally lacking today, but maybe this is just a matter of time and at present is too overwhelming for individuals, groups or a computer's capacity to handle the complexity that is involved. There is an obvious balance between understanding and synthesizing: biology is complex so a reductionist view will not work, it needs to be complex and needs to consider many facets, including humanistic concerns.

\section{ENDNOTES}

1. George Jeronimidis. "Biodynamics" in Architectural Design vol. 74 no. 3 May/June 2004, "Emergence: Morphogenetic Design Strategies", edited by Michael Hensel, Achim Menges and Michael Weinstock, 90-95

2. Ibid 